\title{
Magnetic Resonance Findings of Acute Severe Lower Back Pain
}

\author{
Seon-Yu Kim, M.D., In-Sik Lee, M.D., Ph.D., Bo-Ram Kim, M.D., Jeong-Hoon Lim, M.D., Ph.D., \\ Jongmin Lee, M.D., Ph.D., Seong-Eun Koh, M.D., Ph.D., Seung Beom Kim, M.D., Seung Lee Park, M.D.
}

Department of Rehabilitation Medicine, Konkuk University Medical Center, Konkuk University School of Medicine, Seoul 143-729, Korea

Objective To determine abnormal MRI findings in adults hospitalized with acute severe axial LBP.

Method Sixty patients with back pain were divided into 3 groups consisting of 1) 23 adults with acute axial severe LBP who could not sit up or stand up for several days, but had not experienced previous back-related diseases or trauma (group A), 2) 19 adults who had been involved in a minor traffic accident, and had mild symptoms but not limited mobility (group B), and 3) 18 adults with LBP with radicular pain (group C)., Various MRI findings were assessed among the above 3 groups and compared as follows: disc herniation (protrusion, extrusion), lumbar disc degeneration (LDD), annular tear, high intensity zone (HIZ), and endplate changes.

Results The MRI findings of A group were as follows: disc herniation (87\%), LDD (100\%), annular tear (100\%), HIZ (61\%), and end plate changes (4.4\%). The findings of disc herniation, annular tear, HIZ, and LDD were more prevalent in A group than in B group $(\mathrm{p}<0.01)$. HIZ findings were more prevalent in A group than in group B or group C $(\mathrm{p}<0.05)$.

Conclusion Patients with acute severe axial LBP were more likely to have disc herniation, LDD, annular tear, HIZ. Among LBP groups, there was a significant association of HIZ on MRI with acute severe axial LBP.

Key Words Low back pain, Magnetic resonance imaging

\section{INTRODUCTION}

Acute lower back pain is one of the most common rea-

Received September 21, 2010; Accepted August 5, 2011

Corresponding author: In-Sik Lee

Department of Rehabilitation Medicine, Konkuk University Medical Center, University School of Medicine, 4-12 Hwayang-dong Gwangjingu, Seoul 143-729, Korea

Tel: +82-2-2030-5347, Fax: +82-2-2030-5379, E-mail: mdlis@nate.com (c) This is an open-access article distributed under the terms of the Creative Commons Attribution Non-Commercial License (http:// creativecommons.org/licenses/by-nc/3.0) which permits unrestricted noncommercial use, distribution, and reproduction in any medium, provided the original work is properly cited.

Copyright (C) 2012 by Korean Academy of Rehabilitation Medicine sons for hospital visits. Approximately $33 \%$ of adults experience lower back pain in their life, ${ }^{1}$ and the lifetime prevalence of lower back pain is reported to be $70-85 \%{ }^{2}$ Despite this high prevalence rate, the cause of lower back pain is difficult to accurately diagnose, and its treatment is costly and results in considerable work day loss.

In most cases, the cause of lower back pain, if without any red-flag signs, is a self-controllable disease, and is known to be a benign disease. Red-flag signs include serious neurological defects or organic diseases as tumors, infections, paralytic syndrome, or fractures that require immediate assessment and treatment. ${ }^{3}$

Thus, the first diagnostic approach to determine the 
cause of acute lower back pain is to investigate whether the patient has a neurological defect or an organic disease by investigating his/her medical history and through a physical assessment. This assessment may be helpful in determining the type of lower back pain. ${ }^{4,5}$

Diagnostic imaging may have a critical impact on the proper diagnosis of lower back pain and on the treatment decision by providing accurate anatomical information from a therapeutic viewpoint. Magnetic resonance imaging (MRI) enables the visualization of abnormal vertebral findings that could not have previously been revealed. ${ }^{6,7}$

For example, MRI is generally recommended for patients who need surgical intervention to verify the existence of a tumor or infection and the degree of disc herniation. ${ }^{1,8}$ MRI can also reveal various abnormal findings associated with the lumbar disc and the bone, and can be used as a diagnostic tool for identifying various causes of pain. ${ }^{7}$

Abnormal MRI findings include reduced disc height, reduced signal intensity, change in the disc contour, annular tear, a high-intensity zone (HIZ), and endplate change. .,7,-12 $^{-12}$

Despite these findings, the clinical importance of MRI in the diagnosis of the cause of lower back pain remains controversial, as the incidence of lower back pain is high even in patients who do not have abnormal MRI findings. $^{13}$

Abnormal MRI findings can be observed in $-33 \%$ of patients younger than 40 years, and in almost all patients aged 60-80 years, but its exact cause remains uncertain. $^{14-16}$

Moreover, radiological findings in patients with acute severe lower back pain have not yet been well-studied. This study was conducted to focus on abnormal MRI findings and their clinical relevance in patients who complain of lower back pain that is so severe as to require hospitalization.

\section{MATERIALS AND METHODS}

\section{Subjects}

Twenty-three patients who were hospitalized with acute lower back pain in the Department of Rehabilitation of the Kunkuk University Medical Center in Seoul, Korea during the period of August 2005 to July 2010, were included in group A. An inclusion criterion for group A was having visited the hospital for lower back pain for the first time in their life, and having pain limited to their lower back, without a particular history associated with the lower back and without red-flag signs (infection, fracture, or neurological defects).

Severe lower back pain was defined as pain so severe that the patient had difficulty sitting on a bed at the time of his/her presentation to the hospital. Patients aged $\geq 60$ years were excluded from this study, as most of these patients showed abnormal findings. ${ }^{14-16}$ Of the patients who had no particular history of low back pain, 19 patients who complained of mild lower back pain caused by a simple vehicle accident were assigned to control group $\mathrm{B}$, and 18 patients who complained of severe radiating pain without trauma history and did not let them lead a normal life were assigned to control group C.

Although the control group should have consisted of asymptomatic patients, it was difficult to find such patients. In recent studies, MRI did not reveal meaningful findings for patients who had mild lower back pain caused by a sports activity or a simple vehicle accident. ${ }^{17,18}$ Thus, assuming that of the patients without a particular history related to their lower back, those who complained of mild lower back pain after a simple vehicle accident would not show a change in their MRI findings, those patients were assigned to control group B. In addition, most of the patients with severe radiating pain and who had a history of lower back pain that lasted for a mean of $5.6 \pm 9.4$ months were assigned to control group $\mathrm{C}$ for comparison of chronic lower back pain.

Of the patients with acute severe lower back pain (group A), 13 were male and 10, female. Of the patients with mild lower back pain caused by a simple vehicle accident (control group B), 8 were male and 11 were female. Of the patients with severe radiating lower back pain (Control group C), 11 were male and 7 were female. The patients' mean ages were $34.4 \pm 8.6$ years (group A), 39.4 \pm 9.3 years (control group $B$ ), and $36.3 \pm 12.0$ years (control group C) (Table 1), with no significant differences among the groups $(\mathrm{p}<0.05)$.

\section{Methods}

The MRI findings for the 3 groups were compared. The MRI instrument used in this study was a Signa EXCITE HD 1.5T (General Electronics Co., Milwaukee, USA). T1 (TR/TE, 550/12), and T2 (TR/TE 4000/120) weighted 

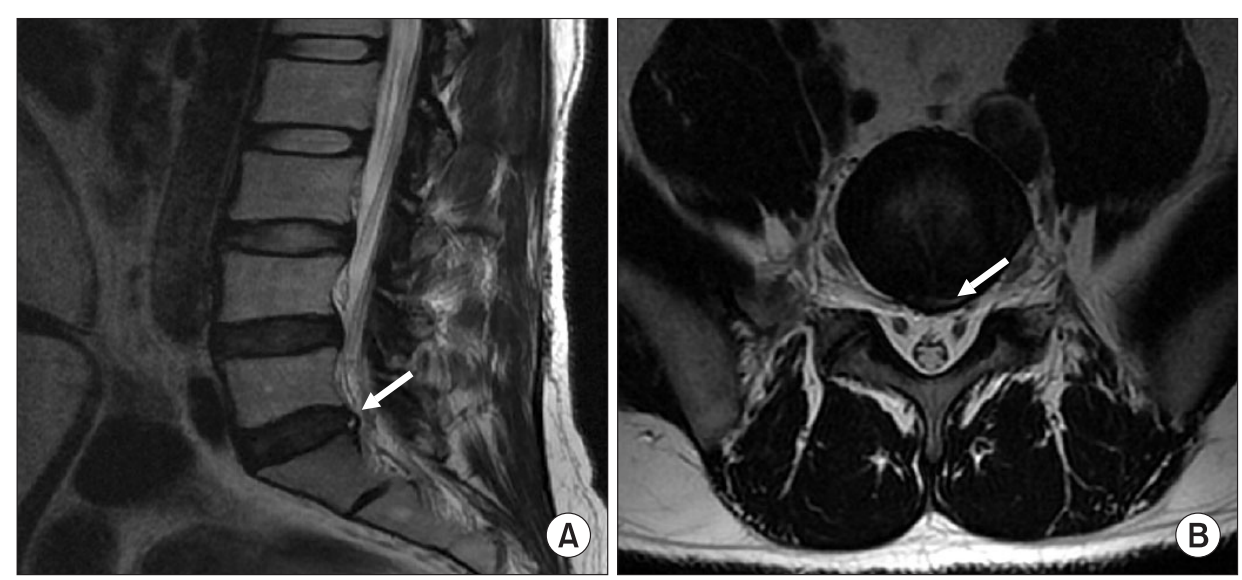

Fig. 1. Magnetic resonance images of high intensity zone (HIZ), (A) The sagittal T2-weighted magnetic resonance image showing a HIZ (arrow) within the posterior annulus at L5-S1, (B) The axial T2-weighted magnetic resonance image shows a HIZ (arrow) within the posterior annulus at L5-S1.

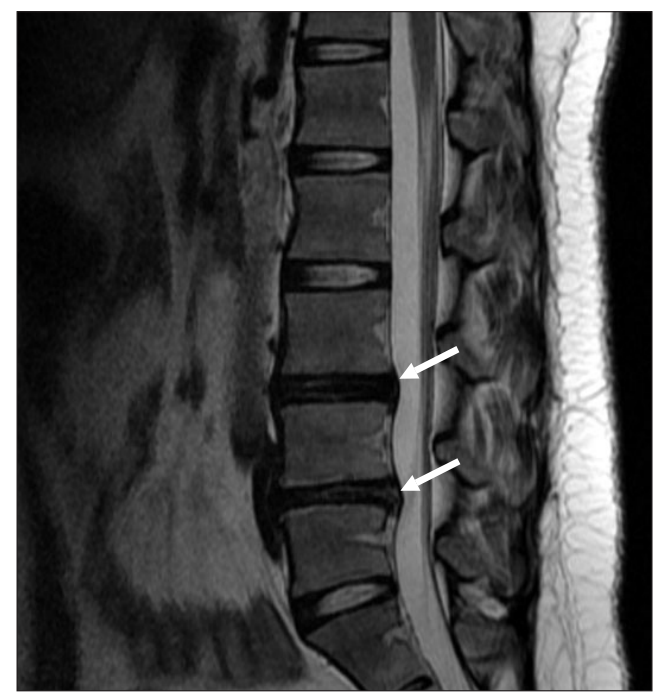

Fig. 2. Magnetic resonance images of lumbar disc degeneration (LDD). The sagittal T2-weighted magnetic resonance image at L3-L4 and L4-L5 levels shows a degenerative signal loss with mild height reduction (arrows).

images were obtained in the sagittal plane, and T1 (TR/ TE, 550/12) and T2 (TR/TE, 4,000/120) weighted images were obtained in the axial plane. The MRI findings showed disc herniation, lumbar disc degeneration (LDD), annular tear, high signal intensity (HIZ), and end plate change (Modic change).

Disc herniation, including disc protrusion and disc extrusion, was defined as an abnormal finding, because disc bulging is known not to have a meaningful association with lower back pain or other abnormal findings for the disc. ${ }^{12,15}$

In addition, annular tear was identified on the T2 weighted image based on the change in the signal of the
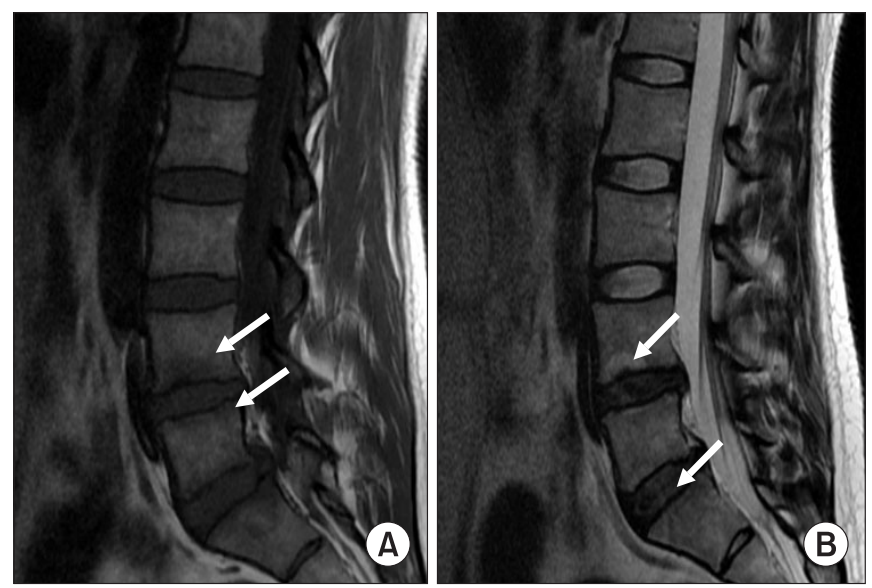

Fig. 3. Magnetic resonance images of Modic change. Modic type I (arrows): hypointense on T1-weighted magnetic resonance image (A) and hyperintense on T2-weighted magnetic resonance image (B).

posterior annulus fibrosus, and the high intensity zone (HIZ) was defined as the local area with a high intensity signal in the posterior annulus fibrosus in the sagittal T2 weighted image, according to Aprill and Bogduk's definition (Fig. 1). ${ }^{19}$

The scale described by Pfirrmann ${ }^{20}$ was used for lumbar disc degeneration (LDD), and a grade $\geq 3$ (a grade at which the overall disc signal is weaker, the boundary between the nucleolus pulposus and the annulus fibrosis is obscure, and the disc height starts decreasing on the MRI scan) was defined as degeneration (Fig. 2). ${ }^{21}$ The Modic change, which Modic et al. ${ }^{22,23}$ defined was used for abnormal findings in the end plate change, and was grouped based on the presence or absence of abnormal findings instead of being classified into types, as the frequency of each type was low (Fig. 3, 4). 
Statistical analysis was performed using SPSS 17.0, and the frequencies of abnormal findings between the groups were compared using the chi-square test with a significance level of $\mathrm{p}<0.05$.

\section{RESULTS}

The frequencies of the MRI findings were as follows: In patients with acute lower back pain (group A), disc
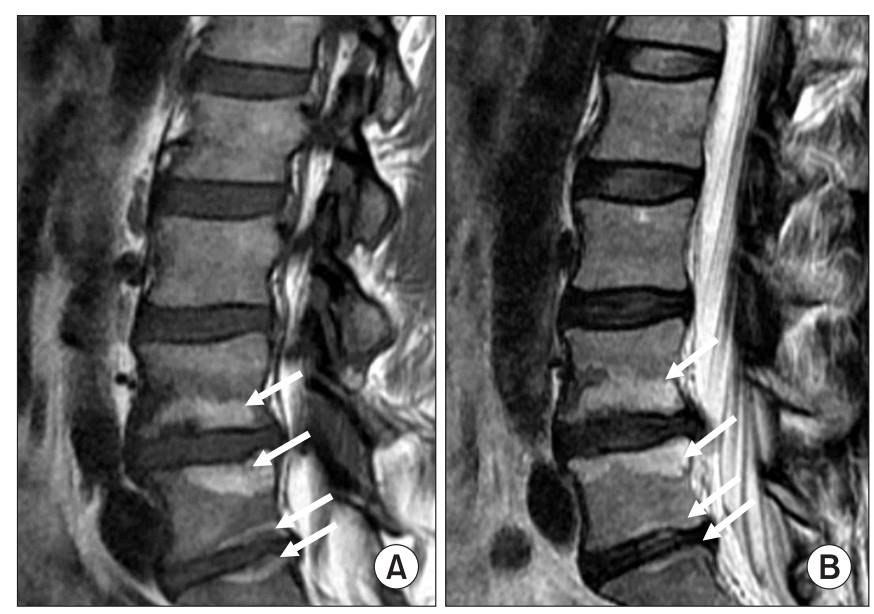

Fig. 4. Magnetic resonance images of Modic change. Modic type II (arrows): hyperintense on T1-weighted magnetic resonance image (A) and hyperintense on T2-weighted magnetic resonance image (B). herniation (87\%), LDD (100\%), annular tear (100\%), HIZ (61\%), and Modic change $(4.4 \%)$; in patients with mild lower back pain caused by a simple vehicle accident (control group B), disc herniation (31.6\%), LDD (47.4\%), annulus tear (26.3\%), HIZ (21.1\%), and Modic change (10.5\%); and in patients with severe radiating lower back pain (control group C), disc herniation (100\%), LDD (100\%), annulus tear (94.4\%), HIZ (16.7\%), and Modic changes $(27.7 \%)$ (Table 1$)$.

In all groups, (80\%) of the disc changes were in L4-5 and L5-S1 (Table 2). There were significant differences in the disc herniation, HDD, annulus tear, and HIZ between the patients with acute severe lower back pain (group A) and

Table 1. General Characteristics of Subjects

\begin{tabular}{lccc}
\hline & $\begin{array}{c}\text { Acute } \\
\text { severe } \\
\text { LBP }\end{array}$ & $\begin{array}{c}\text { Mild LBP } \\
\text { with } \\
\text { minor TA }\end{array}$ & $\begin{array}{c}\text { LBP } \\
\text { with } \\
\text { radicular } \\
\text { pain }\end{array}$ \\
\hline Sex (male/female) & $(13 / 10)$ & $(8 / 11)$ & $(11 / 7)$ \\
Age (years) & $34.4 \pm 8.6$ & $39.4 \pm 9.3$ & $36.3 \pm 12.0$ \\
Disc herniation (\%) & 87 & 31.6 & 100 \\
Disc degeneration (\%) & 100 & 47.4 & 100 \\
Annular tear (\%) & 100 & 26.3 & 94.4 \\
High intensity zone (\%) & 61 & 21.1 & 16.7 \\
End plate change (\%) & 4.4 & 10.5 & 27.7 \\
\hline
\end{tabular}

LBP: Low back pain, TA: Traffic accident

Table 2. Distribution of MR Findings among 3 Groups

\begin{tabular}{|c|c|c|c|c|c|}
\hline & L1-2 & L2-3 & L3-4 & L4-5 & L5-S1 \\
\hline \multicolumn{6}{|l|}{ Acute severe LBP (A) } \\
\hline Disc herniation & 0 & 0 & $2(7.7 \%)$ & $11(42.3 \%)$ & $13(50 \%)$ \\
\hline Disc degeneration & $1(2.5 \%)$ & $1(2.5 \%)$ & $7(17.5 \%)$ & $17(42.5 \%)$ & $14(35 \%)$ \\
\hline Annular tear & $1(2.7 \%)$ & $1(2.7 \%)$ & $4(10.8 \%)$ & $16(43.2 \%)$ & $15(37.5 \%)$ \\
\hline High intensity zone & $1(4.3 \%)$ & $1(4.3 \%)$ & $3(13.0 \%)$ & $11(47.8 \%)$ & $7(30.4 \%)$ \\
\hline \multicolumn{6}{|c|}{ Mild LBP with minor TA (B) } \\
\hline Disc herniation & 0 & $1(14.2 \%)$ & 0 & $2(28.6 \%)$ & $4(57.1 \%)$ \\
\hline Disc degeneration & 0 & $1(8.3 \%)$ & $1(8.3 \%)$ & $6(50.0 \%)$ & $4(33.3 \%)$ \\
\hline Annular tear & 0 & 0 & 0 & $4(57.1 \%)$ & $3(42.9 \%)$ \\
\hline High intensity zone & 0 & 0 & 0 & $4(66.7 \%)$ & $2(33.3 \%)$ \\
\hline \multicolumn{6}{|c|}{ LBP with radicular pain (C) } \\
\hline Disc herniation & 0 & 0 & 0 & $12(50.0 \%)$ & $12(50.0 \%)$ \\
\hline Disc degeneration & 0 & 0 & 3 & $12(42.9 \%)$ & $16(57.1 \%)$ \\
\hline Annular tear & 0 & 0 & 0 & $12(54.5 \%)$ & $10(45.5 \%)$ \\
\hline High intensity zone & 0 & 0 & 0 & $3(100 \%)$ & 0 \\
\hline
\end{tabular}

LBP: Low back pain, TA: Traffic accident 
Table 3. Correlation between the Presence of MR Abnormality and the LBP Groups (chi-square test)

\begin{tabular}{|c|c|c|c|}
\hline & Group & Frequency (\%) & p-value \\
\hline & Acute severe LBP & 87 & ${ }^{*} 0.000<0.01$ \\
\hline \multirow[t]{3}{*}{ Disc herniation } & Mild LBP with minor TA & 31.6 & \\
\hline & LBP with radicular pain & 100 & \\
\hline & Acute severe LBP & 100 & $* 0.000<0.01$ \\
\hline \multirow[t]{3}{*}{ Disc degeneration } & Mild LBP with minor TA & 47.4 & \\
\hline & LBP with radicular pain & 100 & \\
\hline & Acute severe LBP & 100 & $* 0.000<0.01$ \\
\hline \multirow[t]{3}{*}{ Annular tear } & Mild LBP with minor TA & 26.3 & \\
\hline & LBP with radicular pain & 94.4 & \\
\hline & Acute severe LBP & 61 & ${ }^{\dagger} 0.010<0.05$ \\
\hline \multirow[t]{2}{*}{ High intensity zone } & Mild LBP with minor TA & 21.1 & \\
\hline & LBP with radicular pain & 16.7 & \\
\hline
\end{tabular}

${ }^{*}$ Correlation between acute severe LBP and mild LBP with minor TA; ${ }^{\dagger}$ Correlation among all LBP groups LBP: Low back pain, TA: Traffic accident

the control group B $(\mathrm{p}<0.05)$ (Table 3$)$. The proportion of HIZ incidence was significantly higher in group A than in control group $\mathrm{B}$, and in the patients with severe radiating pain (control group $\mathrm{C})(\mathrm{p}<0.05)$ (Table 3$)$. It was difficult to give clinical meaning to the Modic change, as its frequency was low.

\section{DISCUSSION}

In this study, MRI findings in patients with acute severe pain limited to their lower back were analyzed. The anatomical structures that may cause lower back pain include the bone, muscle, fascia, ligaments, disc (exterior annulus fibrosus and posterior disc regions), and nerve roots, and exclude the nucleus pulposus and the ligament flavum.

With the introduction of MRI, it is now possible to reveal abnormal vertebral findings which could not be previously shown. ${ }^{6,7}$ Abnormal findings from an MRI scan are common in asymptomatic patients and many physicians consider them part of degenerative changes due to aging. In addition, the incidence of annulus tear and disc herniation has been reported to increase with age. $^{13-16,24}$

A recent study reported that disc degeneration in the lumbar region reached the intermediate level in a patient in his early 20s. ${ }^{21}$ Thus, LDD and disc herniation without an acute traumatic history can be interpreted as degenerative changes due to aging. ${ }^{13-16,21,24}$
Some studies have reported that in a number of cases, the presence of HIZ indicated that a disc change might have been causing the pain, ${ }^{19,25-29}$ and other studies have reported that no association could be found between these indications. ${ }^{29-31}$ In 2006, Peng et al. ${ }^{32}$ investigated histological changes in specimens obtained from patients with lower back pain to show pathological changes in HIZ.

As a result, Peng et al. ${ }^{32}$ observed granulation tissue wherein capillary vessels were affluent, and that vascular proliferation and invasion of inflammatory cells were present. Considering these reliable indicators of damage of the exterior annular fibrosus in patients with lower back pain, Peng et al. ${ }^{32}$ reported a meaningful association between the findings and lower back pain.

In this study, the incidence of HIZ was significantly higher in patients with acute severe lower back pain than in patients in the control groups (Table 3), which suggests that HIZ in patients with acute severe lower back pain could be attributable to inflammatory pathological changes. There was no significant difference in LDD, which is considered part of degeneration, disc herniation, and annulus fibrosus between patients with severe lower back pain (group A) and patients with radiating lower back pain (control group C). The incidence of LDD, disc herniation, and annulus fibrosus was higher in group $A$ and control group $C$ than in patients with lower back pain caused by a simple vehicle accident (control group B) (Table 3). 
This indicates that when there was no significant difference in age between the groups, the frequency of all the degenerative changes was higher in patients with severe lower back pain without trauma (group A and control group $\mathrm{C}$ ) than in control group $\mathrm{B}$. The differences in occupation, lifestyle, and patient history aggravated the chronic degenerative change; and these fundamental degenerative changes made many patients prone to lower back pain or aggravated their lower back pain. ${ }^{33}$ Though the patients might have experienced lower back pain only once before, interior micro changes caused by environmental or intrinsic factors might have accelerated degenerative changes, and thus, these patients became prone to severe lower back pain. ${ }^{33}$

Though bad posture and management were found to be related to lower back pain in daily life, investigations of patients and their guardians' histories indicate that environmental factors are considerably related to degenerative changes. In addition, most of the patients who experienced severe lower back pain reported that they felt tearing pain in their lower back and a sensation of something being cut off in the pain site after they sprained their back while suddenly bending their lower back or moving. The MRI findings in these patients showed that HIZ was significantly more frequent in group A than in control group B and the patients with acute lower back pain (control group C) (Table 2).

In addition, a recent study showed that HIZ alone has no relationship with discogenic LBP, but has meaning when it accompanies disc protrusion.34 However, this study showed, that HIZ was present in $86 \%(12 / 14)$ of the patients with disc protrusion in group $A(n=19)$ but without disc extrusion, and disc protrusion, was present in $80 \%(4 / 5)$ of the patients with HIZ, which reveals no meaningful association, as the low number of patients with severe lower back pain (group A) does not show a meaningful association.

It is difficult to make a conclusion based on a single study regarding whether or not HIZ can reflect acute inflammatory change in the annulus fibrosus and be a cause of acute lower back pain, but this study is believed to provide clues to the causes of acute lower back pain.

\section{CONCLUSION}

MRI is the most ideal diagnostic tool for explaining basic anatomical abnormalities. The analysis of abnormal MRI findings in this study showed that disc herniation, LDD, annulus tear, and HIZ were significantly higher in patients with severe lower back pain (group A) than in control group $B$, and when compared to groups $B$ and C. HIZ was the only parameter that demonstrated a significant difference.

\section{ACKNOWLEDGEMENTS}

This study was supported by a Grant for Clinical Study 2010 from Konkuk University Hospital.

\section{REFERENCES}

1. Jarvik JG, Deyo RA. Diagnostic evaluation of low back pain with emphasis on imaging. Ann Intern Med 2002; 137: 586-597

2. Andersson GB. Epidemiological features of chronic low back pain. Lancet 1999; 354: 581-585

3. Chou R, Qaseem A, Snow V, Casey D, Cross T Jr, Shekelle P, Owens DK. Diagnosis and treatment of low back pain: a joint clinical practice guideline from the American College of Physicians and the American Pain Society. Ann Intern Med 2007; 147: 478-491

4. Deyo RA, Rainville J, Kent DL. What can the history and physical examination tell us about low back pain? JAMA 1992; 268: 760-765

5. Bigos S, Bowyer O, Braen G, Brown K, Deyo R, Haldeman S, Hart J, Johnson E, Keller R, Kido D, et al. Acute low back pain problems in adults. Clinical Practice Guidline ns 14. AHCPR Publication No. 95-0642 Rockville, MD US Department of Health and Human Services 1994; 95: 1-60

6. 6. Beattie PF, Meyers SP. Magnetic resonance imaging in low back pain: general principles and clinical issues. Phys Ther 1998; 78: 738-753

7. Tehranzadeh J, Andrews C, Wong E. Lumbar spine imaging. Normal variants, imaging pitfalls, and artifacts. Radiol Clin North Am 2000; 38: 1207-1253

8. Anderson RE, Drayer BP, Braffman B, Davis PC, Deck MD, Hasso AN, Johnson BA, Masaryk T, Pomeranz SJ, Seidenwurm D, et al. Acute low back pain-radiculopathy. American College of Radiology. ACR Appropriateness Criteria Radiology 2000; 215: 479-485

9. Nachemson A, Vingard E. Assessment of patients 
with neck and back pain: a best-evidence synthesis. In: Nachemson A, Jonsson E, editors. Neck and back pain: the scientific evidence of causes, diagnosis, and treatment, 1st ed, Philadelphia: Lippincott Williams \& Wilkins, 2000, 189-235

10. Deyo RA, Seinstein JN. Low back pain. N Engl J Med 2001; 344: 363-370

11. Fukuda KG. Proper use of MR imaging for evaluation of low back pain (radiologist' view). Semin Musculoskelet Radiol 2001; 5: 133-136

12. Jarvik JG, Deyo RA. Imaging of lumbar intervertebral disk degeneration and aging, excluding disk herniations. Radiol Clin North Am 2000; 38: 1255-1266

13. Deyo RA. Magnetic resonance imaging of the lumbar spine. Terrific test or tar baby? N Engl J Med 1994; 331: 115-116

14. Boden SD, Davis DO, Dina TS, Patronas, NJ, Wiesel SW. Abnormal magnetic resonance scans of the lumbar spine in asymptomatic subjects. A prospective investigation. J Bone Joint Surg Am 1990; 72: 403-408

15. Jensen MC, Brant-Zawadzki MN, Obuchowski N, Modic MT, Malkasian D, Ross JS. Magnetic resonance imaging of the lumbar spine in people withoutback pain. N Engl J Med 1994; 331: 69-73

16. Stadnik TW, Lee RR, Coen HL, Neirynck EC, Buisseret TS, Osteaux MJ. Annular tears and disk herniation: prevalence and contrast enhancement on MR images in the absence of low back pain or sciatica. Radiology 1998; 206: 49-55

17. Carragee E, Alamin T, Cheng I, Franklin T, Hurwitz E. Does minor trauma cause serious low back illness? Spine 2006; 31: 2942-2949

18. Carragee E, Alamin T, Cheng I, Franklin T, van den Haak E, Hurwitz E. Are first-time episodes of serious LBP associated with new MRI findings? Spine 2006; 6: 624-635

19. Aprill C, Bogduk N. High intensity zone: a diagnostic sign of painful lumbar disc on magnetic resonance imaging. Br J Radiol 1992; 65: 361-369

20. Pfirrmann CW, Metzdorf A, Zanetti M, Hodler J, Boss N. Magnetic resonance classification of lumbar intervertebral disc degeneration. Spine 2001; 26: 18731878

21. Takatalo J, Karppinen J, Niinimaki J, Taimela S, Nayha S, Jarvelin MR, Kyllonen E, Tervonen O. Prevalence of degenerative imaging findings in lumbar magnetic resonance imaging among young adults. Spine 2009; 34: 1716-1721

22. Modic MT, Masaryk TJ, Ross JS, Carter JR. Imaging of degenerative disk disease. Radiology 1988; 168: 177186

23. Modic MT, Steinberg PM, Ross JS, Masaryk TJ, Carter JR. Degenerative disk disease: assessment of changes in vertebral body marrow with MR imaging. Radiology 1988; 166: 193-199

24. Trattnig S, Stelzeneder D, Goed S, Reissegger M, Mamisch TC, Paternostro-Sluga T, Weber M, Szomolanyi P, Welsch GH. Lumbar intervertebral disc abnormalities: comparison of quantitative T2 mapping with conventional MR at 3.0T. Eur Radiol 2010; 20: 2715-2722

25. Schellhas KP, Pollei SR, Gundry CR, Heithoff KB. Lumbar disc high-intensity zone. Correlation of magnetic resonance imaging and discography. Spine 1996; 21: 79-86

26. Saifuddin A, Mitchell R, Taylor BA. Extradural inflammation associated with annular tears: demonstration with gadoliniumenhanced lumbar spine MRI. Eur Spine J 1999; 8: 34-39

27. Lam KS, Carlin D, Mulholland RC. Lumbar disc highintensity zone: the value and significance of provocative discography in the determination of the discogenic pain source. Eur Spine J 2000; 9: 36-41

28. Peng B, Hou S, Wu W, Zhang C, Yang Y. The pathogenesis and clinical significance of a high-intensity zone (HIZ) of lumbar intervertebral disc on MR imaging in the patient with discogenic low back pain. Eur Spine J 2006; 15: 583-587

29. Ricketson R, Simmons JW, Hauser BO. The prolapsed intervertebral disc. The high-intensity zone with discography correlation. Spine 1996; 21: 2758-2762

30. Smith BM, Hurwitz EL, Solsberg D, Rubinstein D, Corenman DS, Dwyer AP, Kleiner J. Interobserver reliability of detecting lumbar intervertebral disc high-intensity zone on magnetic resonance imaging and association of high-intensity zone with pain and anular disruption. Spine 1998; 23: 2074-2080

31. Rankine JJ, Gill KP, Hutchinson CE, Ross ER, Williamson JB. The clinical significance of the highintensity zone on lumbar spine magnetic resonance imaging. Spine 1999; 24: 1913-1919

32. Peng B, Hou S, Wu S, Zhang C, Yang Y. The patho- 
genesis and clinical significance of a high-intensity zone (HIZ) of lumbar intervertebral disc on MR imaging in the patient with discogenic low back pain. Eur Spine J 2006; 15: 583-587

33. Hadjipavlou AG, Tzermiadianos MN, Bogduk N, Zindrick MR. The pathophysiology of disc degeneration a critical review. J Bone Joint Surg Br 2008; 90:
1261-1270

34. Kang CH, Kim YH, Lee SH, Derby R, Kim JH, Chung $\mathrm{KB}$, Sung DJ. Can magnetic resonance imaging accurately predict concordant pain provocation during provocative disc injection? Skeletal Radiol 2009; 38: 877-885 